\title{
Caracterização Anatômica em Diferentes Frações de Cultivares de Capim-elefante (Pennisetum purpureum Schumach.)
}

\author{
Cláudio José Freixieiro Alves de Brito ${ }^{1}$, Francisco Carlos Deschamps ${ }^{2}$
}

\begin{abstract}
RESUMO - O conhecimento da anatomia das gramíneas forrageiras tropicais pode contribuir para sua melhor utilização na alimentação de ruminantes. O objetivo deste trabalho foi determinar a área ocupada pelos diferentes tecidos presentes no colmo e na folha de três cultivares de capim-elefante (Pennisetum purpureum Schumach.). Cinco plantas de cada cultivar foram selecionadas e segmentadas em três partes (apical, mediana e basal), sendo o material coletado 10 semanas após corte de uniformização. O colmo foi separado em duas partes e as folhas foram subdivididas em bainha, limbo e quilha. Observou-se que o floema representa cerca de $2 \%$ da área total dos tecidos. Embora seja um tecido de elevada digestibilidade, esta pequena participação representa pouco para a qualidade final das plantas. A área de tecido epidérmico e tecido vascular lignificado é maior no limbo foliar, principalmente nas folhas jovens. A área de tecido vascular lignificado do colmo aumenta em direção a base da planta. A distância entre os feixes vasculares na bainha está acima de $500 \mu \mathrm{m}$, enquanto no limbo é de $140 \mu \mathrm{m}$. No colmo, a distribuição irregular dos feixes vasculares não permite que esta medida seja utilizada como padrão de comparação entre cultivares. A diferenciação de cultivares através da caracterização anatômica apresenta limitações. Mesmo assim, observou-se que o cultivar Testo apresenta maior área de tecido vascular lignificado e menor área de tecido parenquimático. Enquanto isto, o cultivar Areia apresenta a menor distância entre feixes vasculares na bainha e na quilha com maior área de floema nas folhas.
\end{abstract}

Palavras-chave: anatomia vegetal, forragem, gramíneas, lignina, ruminantes

\section{Tissue Anatomy in Different Fractions of Elephantgrass Cultivars (Pennisetum purpureum Schumach.)}

\begin{abstract}
The knowledge of the anatomy of tropical forage grasses may help to improve its use as ruminant feed. The aim of this paper was to determine the area occupied by different tissues in stem and leaf in three cultivars of elephantgrass (Pennisetum purpureum Schumach.). Five plants of each cultivar were selected and segmented into three parts (apical, median and basal), this material being collected after ten weeks of regrowth. The stems were separated into two parts and the leaves segmented into sheath, limbo and keel. The phloem, a tissue of high digestibility, represented only $2 \%$ of the total tissue area, thus did not affect total plant quality. The area of epidermis and lignified vascular tissues is larger in limbo, mainly in young leaves. In the stem, the area of vascular lignified tissue increases towards the bottom of the plant. The distance between bundle sheaths in the leaf sheath is over $500 \mu \mathrm{m}$, while in limbo it is $140 \mu \mathrm{m}$. It was difficult to determine the correct distance among bundle sheaths in stems due to their uneven distribution. Limitations were observed in separating cultivars through anatomy profile. Even so, cultivar Testo showed the greatest vascular lignified tissue area and the lowest area of parenchymal tissue. On the other hand, cultivar Areia showed the smallest distance among bundle sheaths in the leaf sheath and keel, and the greatest area of phloem in leaves.
\end{abstract}

Key Words: forage, grasses, lignin, plant anatomy, ruminants

\section{Introdução}

O capim-elefante (Pennisetum purpureum Schumach.) é uma gramínea forrageira bastante utilizada para alimentação de bovinos. Mesmo assim, apresenta restrições do ponto de vista de qualidade, já que sua produção é estacional e o valor nutricional se reduz drasticamente com a maturação (SALERNO et al., 1990). Por outro lado, pela sua grande diversi- dade genética, o capim-elefante apresenta características diferenciadas entre os diversos cultivares. Em geral, o envelhecimento das plantas é acompanhado pelo espessamento e lignificação das paredes celulares, estando ambos relacionados à redução na digestibilidade (WILSON, 1997; ALVES DE BRITO et al., 1999). A quantificação de tecidos em plantas forrageiras tem sido relacionada ao valor nutritivo das espécies em parâmetros como a digestibilidade 
(HANNA et al., 1973; AKIN e BURDICK, 1975; WILSON, 1993, 1997), degradação ruminal (ENGELS e SCHUURMANS, 1992; WILSON, 1997; ALVES DE BRITO et al., 1999) ou composição bromatológica (VENTRELLA, 1995; VENTRELLA et al., 1997a, 1997b). Dessa forma, a caracterização anatômica das forrageiras pode contribuir para a melhor compreensão dos fatores que envolvem a digestão dos tecidos das forrageiras pelos ruminantes.

No presente trabalho foram quantificadas as áreas ocupadas pelos diferentes tecidos presentes no colmo e na folha de três cultivares de capim-elefante (Pennisetum purpureum Schumach.), separados em três regiões da planta (apical, mediana e basal).

\section{Material e Métodos}

O material vegetal constitui-se dos cultivares Empasc-307 TESTO, Empasc-309-AREIA e ROXO de capim-elefante ( $P$. purpureum Schumach.), os quais encontravam-se estabelecidos na Estação Experimental da EPAGRI S/A em Itajaí - SC (26o54'28"S, 48039'43"W, 5 m.s.m.), em parcelas de $10 \mathrm{~m}$ x $10 \mathrm{~m}$. Dez semanas após o corte de uniformização, realizado em 26/11/96, foram selecionadas as plantas em um delineamento em blocos ao acaso, com cinco repetições sendo retiradas oito plantas de cada parcela (40 no total). De cada parcela foi selecionada 1 planta (5 no total), das quais foram retiradas as frações constituídas de colmos e folhas. Estas últimas foram subdivididas em bainha foliar, limbo (asas) e quilha (nervura central), conforme terminologia proposta por METCALFE (1960) (Figuras 1 e 2). Coletou-se em três regiões da planta, denominadas de apical, mediana e basal. Para o estabelecimento dos limites destas regiões, tomou-se o colmo como referência. As folhas foram separadas manualmente do colmo e este foi dividido ao meio, denominando-se a fração inferior de basal e a porção superior de mediana. As folhas coletadas nestas duas regiões ficaram constituídos de bainhas foliares, limbos e quilhas, além das respectivas frações de colmo. Já na região denominada de apical, considerou-se somente as frações foliares. As folhas mortas, presentes na região basal, não foram utilizadas para o estudo anatômico. A separação da quilha, que no capimelefante é bastante pronunciada, foi feita com auxilio de uma lâmina de inox, buscando-se a posição de inserção do limbo na quilha. As amostras foram então fixadas em F.A.A. $70 \%$ por $48 \mathrm{~h}$ e conservadas em álcool 70\% (JOHANSEN, 1940). Para a confecção do laminário, as amostras foram incluídas em glicol metacrilato (GMA) JB4 (Polysciences, Inc.). O seccionamento foi realizado em micrótomo rotatório Spencer 820, com as secções apresentando espessura de 4 a $5 \mu \mathrm{m}$, sendo coradas com Fucsina Básica e Azul de Astra conforme ALVES DE BRITO e ALQUINI (1996).

Para o estudo histológico da anatomia quantitativa utilizaram-se cinco repetições, com as áreas dos tecidos sendo determinadas a partir de desenhos esquemáticos. Os desenhos foram efetuados com auxílio de microscópio de projeção BIOTEC/NIKON e os tecidos separados de acordo com a natureza da parede celular, conforme metodologia utilizada por ALVES DE BRITO et al. (1999). Neste caso, o tecido epidérmico foi constituído de células
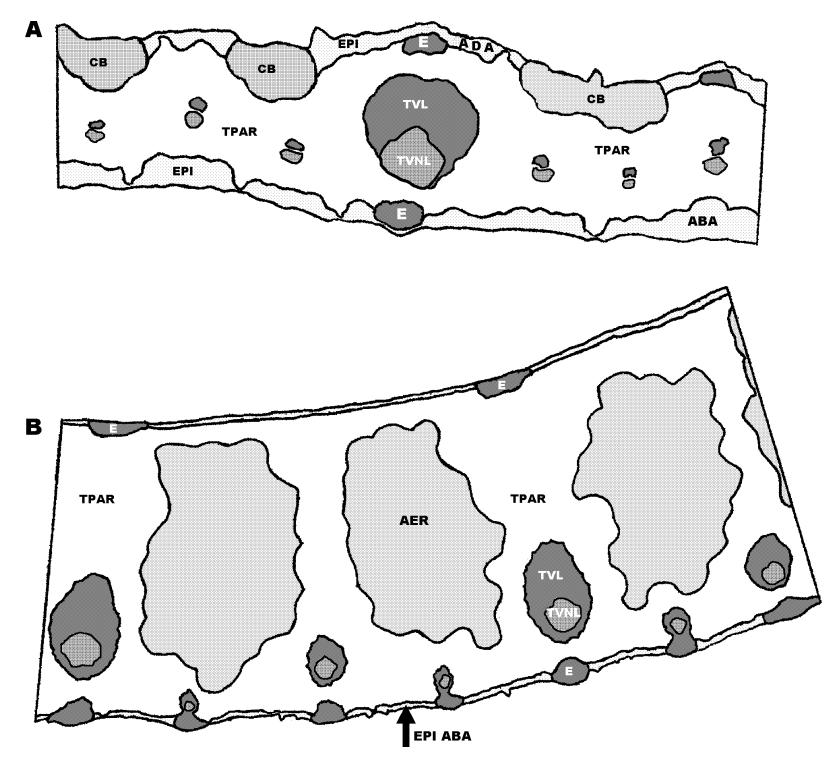

Figura 1 - Representações esquemáticas das secções transversais de $P$. purpureum. A - região do limbo (asas) foliar; B - bainha foliar. CB- células buliformes; EPI ADA - epiderme abaxial; EPI ABA - epiderme abaxial; E- esclerênquima; TPAR tecido parenquimático; TVL - tecido vascular lignificado; TVNL - tecido vascular não lignificado; AER - aerênquima.

Figure 1 - Schematically representations of $P$. purpureum crosssections. A - leaf limbo (wings) region; $B$ - leaf sheath. $C B$ - buliform cells; EPI ADA - adaxial epidermis; EPI $A B A$ - abaxial epidermis; TPAR - parenchymal tissue; TVL - lignified vascular tissue; TVNL - non lignified vascular tissue; AER - aerenchyma. 

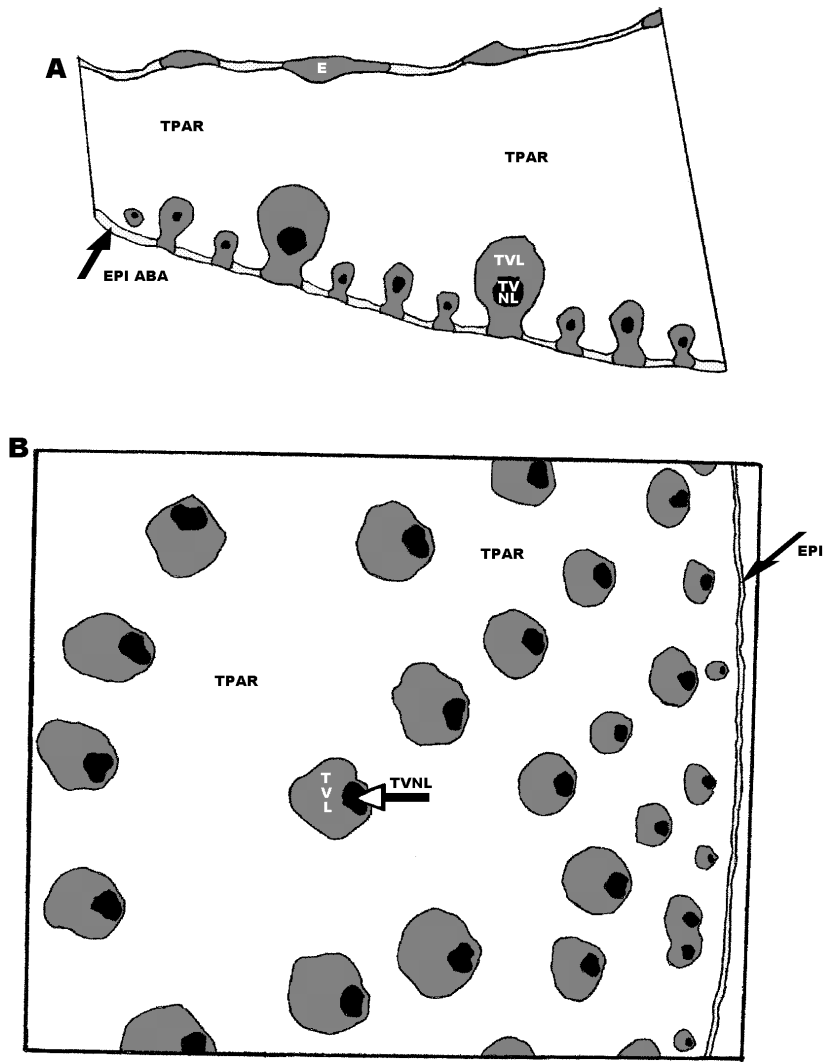

Figura 2 - Representações esquemáticas das secções transversais de $P$. purpureum. A - região da quilha foliar; B-caule. EPI-epiderme; EPIABA- epiderme abaxial; E- esclerênquima; TPAR - tecido parenquimático; TVL - tecido vascular lignificado; TVNL - tecido vascular não lignificado.

Figure 2 - Schematically representations of $P$. purpureum crosssections. A - leaf keel region; $B$ - stem. EPI - epidermis; EPI ABA - abaxial epidermis; TPAR - parenchymal tissue; TVL - lignified vascular tissue; TVNL - non lignified vascular tissue.

epidérmicas, exceto tricomas e células buliformes; tecido vascular lignificado + esclerênquima $=$ células com paredes lignificadas presentes nos feixes vasculares; tecido vascular não lignificado $=$ basicamente floema; tecido parenquimático = incluindo as células buliformes (devido à natureza de suas paredes). Foi determinada também a distância entre os feixes vasculares nas frações foliares. O aerênquima, quando presente na bainha foliar, foi mensurado e subtraído da área de tecido parenquimático.

Os desenhos foram posteriormente digitalizados em mesa digitalizadora DIGICOM modelo 1812, acoplada a microcomputador e as respectivas áreas, determinadas com auxílio do software de planimetria SPLAN. Este software foi disponibilizado pelo CINAG (Centro de Informática na Agricultura), da Faculdade de Ciências Agronômicas da UNESP, Botucatu -SP.

Para análise estatística, considerou-se o delineamento experimental inteiramente ao acaso com três tratamentos (cultivares) e cinco repetições. Os resultados correspondentes às porcentagens dos respectivos tecidos foram transformados em ARCOSEN $\sqrt{x}$ e, posteriormente, submetidos à análise de variância, com as médias comparadas por intermédio do teste de Tukey a 5\% de probabilidade. O software utilizado foi ESTAT, desenvolvido pelo Pólo de Informática da UNESP/Jaboticabal.

\section{Resultados e Discussão}

O ciclo de crescimento das forrageiras está caracterizado pela emissão de novas folhas à medida que a planta se desenvolve. Com o tempo, as folhas emitidas se tornam maduras, comprometendo sua qualidade como forrageira. Nas espécies utilizadas para pastejo, a renovação dos tecidos é estimulada pela apreensão realizada pelos próprios animais. Já nas espécies para corte, é a freqüência de corte que determina a taxa de renovação dos tecidos e deposição de matéria seca das forrageiras. Neste sentido, se uma planta forrageira é deixada crescer livremente, podem-se encontrar folhas e frações do colmo em diversos estágios de crescimento. Assim, por exemplo, a porção basal do colmo é formada por tecidos maduros e de difícil digestão pelos ruminantes. Este princípio foi adotado no presente estudo, acompanhando-se o desenvolvimento dos diversos órgãos da planta desde a sua emissão até a senescência. As principais modificações observadas nas áreas ocupadas pelos tecidos, nos diversos órgãos dos três cultivares estudados, estão apresentados nas Tabelas 1, 2, 3 e 4 .

$\mathrm{Na}$ Tabela 1 são apresentados os resultados referentes às modificações observadas nas áreas do limbo foliar. Nesta fração, pode-se observar que a área ocupada pelo tecido epidérmico apresentou redução no sentido apical/basal de inserção das folhas. Este fenômeno se deve ao aumento no volume das células buliformes, cujas áreas estão incluídas na porcentagem de tecido parenquimático. Com relação à comparação entre cultivares, o ROXO apresentou 
maior área (média na planta) de tecido epidérmico, sem nenhuma explicação aparente.

Ao contrário do esperado, as áreas de tecidos lignificados presentes no limbo (Tabela 1), quando observadas no sentido apical-basal, não foram alteradas $(\mathrm{p}>0,05)$.

Em espécies como Panicum, já foi descrita a redução nas áreas de tecidos lignificados no sen- tido apical/basal (WILSON, 1976; RODELLA et al., 1984). Por outro lado, parece que estes achados não são definitivos, já que em Hemarthria e Brachiaria, bem como no cultivar ROXO, a lignificação dos tecidos do limbo aumenta no sentido apical-basal (ALVES DE BRITO e DESCHAMPS, 1998; ALVES DE BRITO e RODELLA, 1999). Nesse sentido, o tecido

Tabela 1 - Área dos tecidos (\%) e distância entre feixes vasculares no limbo de duas regiões de cultivares de Pennisetum purpureum

Table 1 - Limbo tissue area (\%) and bundle sheath distance in two regions of Pennisetum purpureum cultivars

\begin{tabular}{|c|c|c|c|c|}
\hline & Testo & Areia & Roxo & $\begin{array}{c}\text { Média }(\mathrm{R}) \\
\text { Average }\end{array}$ \\
\hline $\begin{array}{l}\text { Regiões } \\
\text { Regions }\end{array}$ & \multicolumn{4}{|c|}{$\begin{array}{l}\text { Tecido epidérmico } \\
\text { Epidermal tissue }\end{array}$} \\
\hline $\begin{array}{l}\text { Apical } \\
\text { Apical } \\
\text { Mediana } \\
\text { Median } \\
\text { Média }(\mathrm{C}) \\
\text { Average } \\
\end{array}$ & $\begin{array}{c}16,4 \pm 0,69^{\mathrm{Aa}} \\
9,1 \pm 0,32^{\mathrm{Bb}} \\
11,3^{\mathrm{b}}\end{array}$ & $\begin{array}{c}14,0 \pm 1,99^{\mathrm{Aa}} \\
12,8^{\mathrm{b}}\end{array}$ & $\begin{array}{c}16,9 \pm 1,56^{\mathrm{Aa}} \\
13,1 \pm 0,54^{\mathrm{Ba}} \\
15,0^{\mathrm{a}}\end{array}$ & $\begin{array}{l}15,0^{\mathrm{A}} \\
12,1^{\mathrm{B}}\end{array}$ \\
\hline \multicolumn{5}{|c|}{$\begin{array}{l}\text { Tecido vascular lignificado + esclerênquima } \\
\text { Lignified vascular tissue }+ \text { sclerenchyma }\end{array}$} \\
\hline $\begin{array}{l}\text { Apical } \\
\text { Apical } \\
\text { Mediana } \\
\text { Median } \\
\text { Média (C) } \\
\text { Average }\end{array}$ & $\begin{array}{c}29,4 \pm 1,64^{\text {n.s. }} \\
23,4 \pm 2,50^{\text {n.s. }} \\
26,4^{\mathrm{a}}\end{array}$ & $\begin{array}{c}26,5 \pm 2,20^{\text {n.s }} . \\
21,9 \pm 1,29^{\text {n.s. }} \\
24,2^{\mathrm{a}}\end{array}$ & $\begin{array}{c}24,9 \pm 2,18^{\text {n.s. }} \\
26,0 \pm 1,72^{\text {n.s. }} \\
25,5^{\mathrm{a}}\end{array}$ & $\begin{array}{l}26,9^{\mathrm{A}} \\
23,8^{\mathrm{B}}\end{array}$ \\
\hline \multicolumn{5}{|c|}{$\begin{array}{c}\text { Tecido vascular não lignificado } \\
\text { Non lignified vascular tissue }\end{array}$} \\
\hline $\begin{array}{l}\text { Apical } \\
\text { Apical } \\
\text { Mediana } \\
\text { Median } \\
\text { Média }(\mathrm{C}) \\
\text { Average }\end{array}$ & $\begin{array}{c}2,4 \pm 0,13^{\mathrm{Ab}} \\
2,5^{\mathrm{b}}\end{array}$ & $\begin{array}{c}2,9 \pm 0,32^{\mathrm{Ba}} \\
4,5 \pm 0,55^{\mathrm{Aa}} \\
3,9^{\mathrm{a}}\end{array}$ & $\begin{array}{c}2,3 \pm 0,18^{\mathrm{Aa}} \\
2,2 \pm 0,19^{\mathrm{Ab}} \\
2,3^{\mathrm{b}}\end{array}$ & $\begin{array}{l}2,6^{\mathrm{B}} \\
3,2^{\mathrm{A}}\end{array}$ \\
\hline \multicolumn{5}{|c|}{$\begin{array}{c}\text { Tecido parenquimático } \\
\text { Parenchymal tissue }\end{array}$} \\
\hline $\begin{array}{l}\text { Apical } \\
\text { Apical } \\
\text { Mediana } \\
\text { Median } \\
\text { Média }(\mathrm{C}) \\
\text { Average }\end{array}$ & $\begin{array}{c}51,5 \pm 2,40^{\mathrm{Bb}} \\
65,0 \pm 2,03^{\mathrm{Aa}} \\
58,3^{\mathrm{a}}\end{array}$ & $\begin{array}{c}59,0 \pm 3,05^{\mathrm{Aa}} \\
59,7 \pm 1,96^{\mathrm{Ab}} \\
59,4^{\mathrm{a}}\end{array}$ & $\begin{array}{c}55,9 \pm 3,50^{\mathrm{Ab}} \\
58,7 \pm 2,93^{\mathrm{Ab}} \\
57,3^{\mathrm{a}}\end{array}$ & $\begin{array}{l}55,5^{\mathrm{B}} \\
61,1^{\mathrm{A}}\end{array}$ \\
\hline \multicolumn{5}{|c|}{$\begin{array}{c}\text { Distância entre feixes vasculares }(\mu \mathrm{m}) \\
\text { Bundle sheath distance - } \mu \mathrm{m}\end{array}$} \\
\hline $\begin{array}{l}\text { Apical } \\
\text { Apical }\end{array}$ & $122,5 \pm 22,31^{\text {n.s. }}$ & $148,6 \pm 34,95^{\text {n.s. }}$. & $139,9 \pm 13,00^{\text {n.s. }}$ & $137,0^{\mathrm{A}}$ \\
\hline $\begin{array}{l}\text { Mediana } \\
\text { Median }\end{array}$ & $134,7 \pm 30,99^{\text {n.s. }}$ & $145,8 \pm 26,35^{\text {n.s. }}$ & $140,6 \pm 27,62^{\text {n.s. }}$ & $140,4^{\mathrm{A}}$ \\
\hline $\begin{array}{l}\text { Média }(\mathrm{C}) \\
\text { Average }\end{array}$ & $128,6^{\mathrm{a}}$ & $147,2^{\mathrm{a}}$ & $140,3^{\mathrm{a}}$ & \\
\hline
\end{tabular}

(C) cultivares; (R) - posição de inserção na planta. Letras iguais maiúsculas na coluna e minúsculas na linha não diferem ( $p>0,05)$.

(C) cultivars; $(R)$ - insertion position in plant. Same capital letters in column and small in a row do not differ $(p>.05)$. 
vascular não lignificado do cultivar AREIA apresentou incremento $(\mathrm{p}<0,05)$ em sua área, principalmente pela diferenciação e crescimento das células do floema. Pode-se considerar que na região apical estas células são jovens e ainda em estádio de diferenciação.

A distância entre feixes no limbo não apresentou variação significativa $(p>0,05)$. Em outras gramíneas como a Brachiaria, esta distância pode apresentar redução com a maturidade da folha, como constataram ALVES DE BRITO e RODELLA (1999). As alterações apresentadas pelas diversas espécies para distância entre os feixes vasculares podem indicar que esta característica esteja diretamente ligada ao gênero a que a planta pertence. Não foram observadas diferenças para esta característica $(\mathrm{p}>0,05)$,

Tabela 2 - Área dos tecidos (\%) e distância entre feixes vasculares na quilha de duas regiões de cultivares de Pennisetum purpureum

Table 2 - Keel tissue area (\%) and bundle sheath distance in two regions of Pennisetum purpureum cultivars

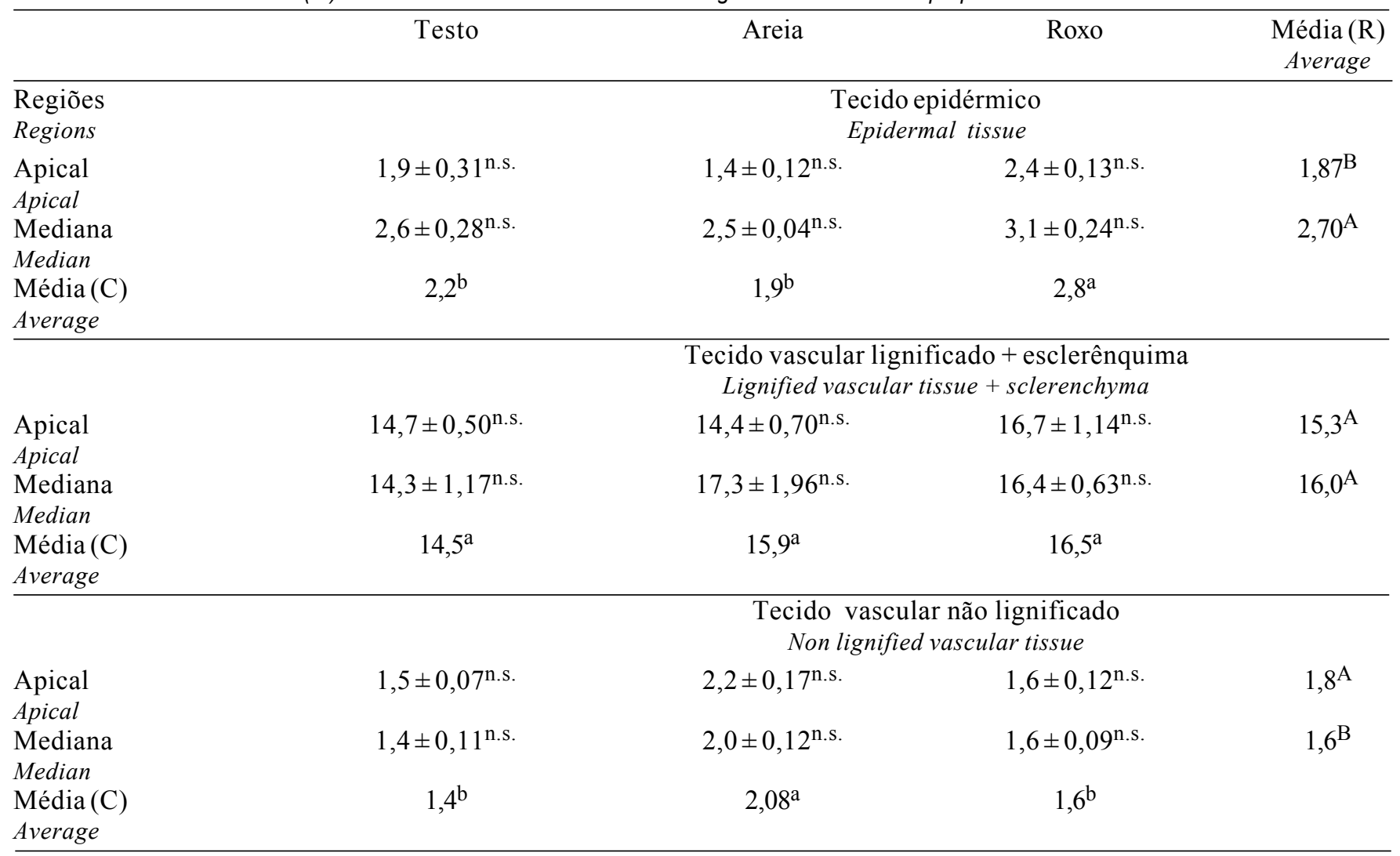

Tecido parenquimático

Parenchymal tissue

$\begin{array}{lcccc}\text { Apical } & 81,9 \pm 0,57^{\mathrm{Aa}} & 82,0 \pm 0,54^{\mathrm{Aa}} & 80,2 \pm 0,50^{\mathrm{Aa}} & 81,4^{\mathrm{A}} \\ \begin{array}{l}\text { Apical } \\ \text { Mediana }\end{array} & 81,9 \pm 1,02^{\mathrm{Aa}} & 78,2 \pm 1,86^{\mathrm{Bb}} & 78,9 \pm 0,52^{\mathrm{Ab}} & 79,7^{\mathrm{B}} \\ \begin{array}{l}\text { Median } \\ \text { Média }(\mathrm{C})\end{array} & 81,9^{\mathrm{a}} & 80,1^{\mathrm{ab}} & 79,6^{\mathrm{b}} & \\ \text { Average } & & & \end{array}$

Distância entre feixes vasculares $(\mu \mathrm{m})$ Bundle sheath distance - $\mu m$

$\begin{array}{lcccc}\text { Apical } & 318,4 \pm 30,28^{\mathrm{Aa}} & 262,4 \pm 21,47^{\mathrm{Ab}} & 264,8 \pm 13,97^{\mathrm{Bb}} & 281,9^{\mathrm{B}} \\ \text { Apical } & 344,0 \pm 34,29^{\mathrm{Aa}} & 280,8 \pm 23,73^{\mathrm{Ab}} & 356,0 \pm 23,68^{\mathrm{Aa}} & 326,9^{\mathrm{A}} \\ \begin{array}{l}\text { Mediana } \\ \text { Median }\end{array} & 331,2^{\mathrm{a}} & 271,6^{\mathrm{b}} & 310,4^{\mathrm{a}} & \\ \begin{array}{l}\text { Média }(\mathrm{C}) \\ \text { Average }\end{array} & & & \end{array}$

(C) cultivares; (R) - posição de inserção na planta. Letras iguais maiúsculas na coluna e minúsculas na linha não diferem ( $p>0,05)$.

(C) cultivars; $(R)$ - insertion position in plant. Same capital letters in column and small in a row do not differ $(p>.05)$. 
entre os cultivares, sendo que o cv. AREIA, apresentou feixes um pouco mais distantes. Isto pode facilitar a ruptura do limbo no momento da apreensão pelos animais, principalmente no caso dos bovinos.

A fração quilha (Tabela 2) apresentou incremento na porcentagem de tecido epidérmico no sentido apical-basal $(\mathrm{p}<0,05)$. Tal fato deve-se principalmente ao aumento no volume das células epidérmicas. Quanto aos cultivares, o cv. ROXO revelou-se com maior área deste tecido $(\mathrm{p}<0,05)$, da mesma forma como ocorreu no limbo.

A área de tecido vascular lignificado + esclerênquima na quilha não variou nas diferentes regiões, nem foram observadas diferenças entre os cultivares. A quilha apresentou-se bastante lignificada, com valores próximos aos encontrados no colmo. Tal fato pode estar associado à função de sustentação da lâmina foliar exercida pela quilha. ALVES DE BRITO et al. (1999) determinaram que a quilha apresenta elevado grau de lignificação, sugerindo ser uma fração bastante limitante à degradação pela biota ruminal. $\mathrm{O}$ incremento no teor de lignina pode estar associado ao espessamento da parede celular, principalmente da parede secundária. Isto explica porque se observa o incremento no teor de lignina sem alteração na área de tecido lignificado. O tecido vascular não lignificado apresentou redução $(p<0,05)$ no sentido apical-basal, sendo que a maior área deste tecido foi determinada no cv. AREIA.

$\mathrm{Na}$ área de tecido parenquimático houve redução $(\mathrm{p}<0,05)$ no sentido apical-basal, relacionado principalmente ao incremento observado na área de tecido epidérmico. Os cvs. TESTO e AREIA apresentaram os valores mais elevados deste tecido, sugerindo melhor potencial de degradação. O tecido parenquimático apresenta elevadas taxas de degradação e ocupa grande parte da área nos diferentes órgãos e frações, sendo portanto, muito importante na qualidade da forrageira.

Na quilha, houve distanciamento entre os feixes vasculares no sentido apical-basal (Tabela 2). Em parte, isto pode ter ocorrido pelo próprio alargamento da lâmina foliar. Entre os cultivares, os cvs. ROXO e TESTO apresentaram feixes mais distantes. Tais resultados podem ser relacionados à morfologia destes cultivares, já que esses mesmos cultivares apresentaram lâminas foliares mais largas do que o cv. AREIA.

A área de tecido epidérmico na bainha foliar (Tabela 3) apresentou-se maior na região mediana e com maior proporção no cv. AREIA e ROXO. Já os tecidos lignificado, vascular não lignificado e parenquimático não apresentaram variações significativas. Tal fato também foi relatado por outros autores como WILSON (1976), CHERNEY e MARTEN (1982) e ALVES DE BRITO e RODELLA (1999), os quais afirmaram que a proporção de tecidos na bainha foliar não varia com a maturidade. Quanto aos cultivares, apenas o cv. AREIA diferenciou-se dos demais, apresentando maior área de tecido vascular não lignificado.

Assim como na quilha, na bainha houve aumento na distância entre feixes $(\mathrm{p}<0,05)$ sendo os cvs. ROXO e TESTO os que apresentaram distâncias maiores. A maior distância entre feixes vasculares encontrada na bainha em relação à quilha e principalmente ao limbo, pode estar associada à presença do aerênquima, o qual se constitui de lacunas formadas entre os feixes vasculares da bainha foliar.

Observa-se na Tabela 4 que o colmo apresenta uma área extremamente reduzida de epiderme, próxima a $0,6 \%$, a qual sofre incremento $(p<0,05)$ no sentido apical-basal. Contribuem para isto a lignificação das paredes periclinais externas e anticlinais, além do espessamento da cutícula que ocorre na senescência da bainha foliar. O incremento da epiderme no sentido apical-basal pode estar relacionado à proteção do colmo. Na região mediana o colmo está totalmente envolto pela bainha foliar, enquanto na região basal, a senescência da bainha expõe o colmo diretamente ao ambiente.

No colmo, o tecido vascular lignificado apresentou aumento significativo $(\mathrm{p}<0,05)$ em sua área no sentido apical-basal, assim como descrito por ALVES DE BRITO e DESCHAMPS (1998).

Entre os cultivares, as áreas de tecidos lignificados são distintas, sendo o cv. AREIA o que apresentou a área menor e o cv. TESTO, a maior. Assim como discutido na fração quilha, este tecido compromete a qualidade da forrageira, principalmente em estádios de crescimento em que o colmo tenha grande participação no peso seco total.

No colmo, o tecido vascular não lignificado não apresentou variação entre as regiões ( $>00,05)$, mesmo entre os cultivares. Deve-se considerar que a área deste tecido tem reduzida participação na área total dos tecidos, representando menos de $2 \%$ em média.

Houve redução na área de tecido parenquimático no sentido apical-basal, principalmente pelo aumento da área lignificada de parênquima. Entre os cultiva- 
Tabela 3 - Área dos tecidos (\%) e distância entre feixes vasculares na bainha foliar de três regiões de cultivares de Pennisetum purpureum

Table 3 - Leaf sheath tissue area (\%) and bundle sheath distance in three regions of Pennisetum purpureum cultivars

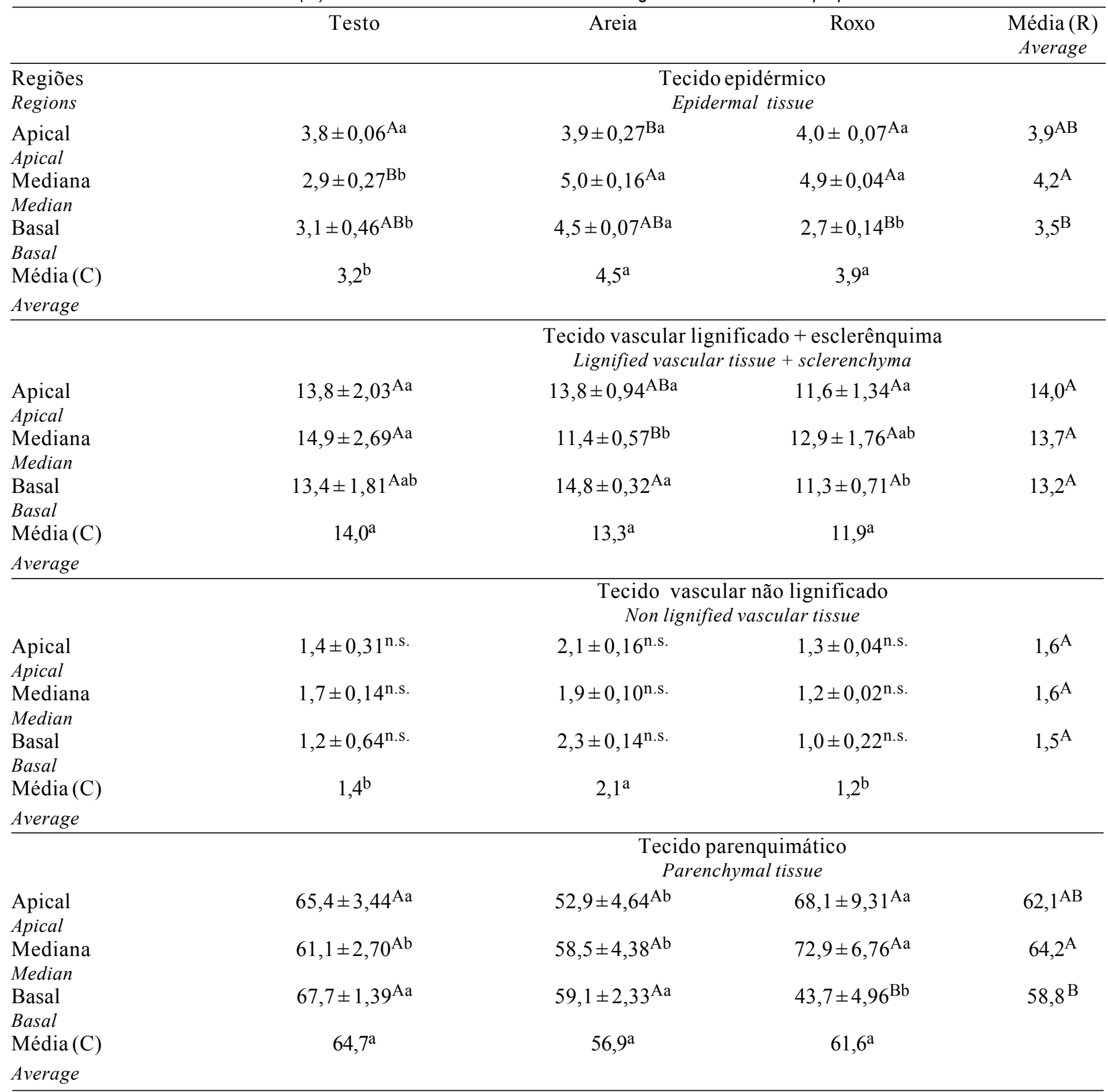

Distância entre feixes vasculares $(\mu \mathrm{m})$

Bundle sheath distance - $\mu m$

$\begin{array}{lccc}\text { Apical } & 596,0 \pm 39,60^{\mathrm{Ba}} & 477,5 \pm 3,54^{\mathrm{Ab}} & 574,0 \pm 8,49^{\mathrm{Ba}} \\ \begin{array}{l}\text { Apical } \\ \text { Mediana }\end{array} & 684,0 \pm 5,66^{\mathrm{Aa}} & 454,0 \pm 36,7^{\mathrm{Ab}} & 610,0 \pm 14,14^{\mathrm{Ba}} \\ \begin{array}{l}\text { Median } \\ \text { Basal } \\ \text { Basal } \\ \text { Média (C) }\end{array} & 640,0 \pm 56,57^{\mathrm{ABb}} & 460,0 \pm 16,97^{\mathrm{Ac}} & 860,0 \pm 28,28^{\mathrm{Aa}} \\ \text { Average } & 640,0^{\mathrm{a}} & 464,7^{\mathrm{b}} & 653,3^{\mathrm{A}} \\ \end{array}$

Average

(C) cultivares; (R) - posição de inserção na planta. Letras iguais maiúsculas na coluna e minúsculas na linha não diferem significativamente $(p>0,05)$.

(C) cultivars; $(R)$ - insertion position in plant. Same capital letters in column and small letter in line do not differ ( $p>.05)$. 
Tabela 4 - Área dos tecidos (\%) presentes no colmo de duas regiões de cultivares de Pennisetum purpureum Table 4 - Stem tissue area (\%) found in two regions of Pennisetum purpureum cultivars

\begin{tabular}{|c|c|c|c|c|}
\hline & Testo & Areia & Roxo & $\begin{array}{l}\text { Média }(\mathrm{R}) \\
\text { Average }\end{array}$ \\
\hline $\begin{array}{l}\text { Regiões } \\
\text { Regions }\end{array}$ & \multicolumn{4}{|c|}{$\begin{array}{l}\text { Tecido Epidérmico } \\
\text { Epidermal tissue }\end{array}$} \\
\hline $\begin{array}{l}\text { Mediana } \\
\text { Median } \\
\text { Basal } \\
\text { Basal } \\
\text { Média (C) } \\
\text { Average }\end{array}$ & $\begin{array}{c}0,5 \pm 0,04^{\text {n.s. }} \\
0,6 \pm 0,06^{\text {n.s. }} \\
0,6^{\mathrm{a}}\end{array}$ & $\begin{array}{c}0,6 \pm 0,04^{\text {n.s. }} \\
0,7 \pm 0,16^{\text {n.s. }} \\
0,6^{\mathrm{a}}\end{array}$ & $\begin{array}{c}0,5 \pm 0,04^{\text {n.s. }} \\
0,7 \pm 0,66^{\text {n.s. }} \\
0,6^{\mathrm{a}}\end{array}$ & $\begin{array}{l}0,5^{\mathrm{B}} \\
0,7^{\mathrm{A}}\end{array}$ \\
\hline \multicolumn{5}{|c|}{$\begin{array}{l}\text { Tecido vascular lignificado + esclerênquima } \\
\text { Lignified vascular tissue }+ \text { sclerenchyma }\end{array}$} \\
\hline $\begin{array}{l}\text { Mediana } \\
\text { Median } \\
\text { Basal } \\
\text { Basal } \\
\text { Média (C) } \\
\text { Average }\end{array}$ & $\begin{array}{c}15,4 \pm 1,41^{\text {n.s. }} \\
21,2 \pm 2,78^{\text {n.s. }} \\
18,3^{\mathrm{a}}\end{array}$ & $\begin{array}{c}14,8 \pm 1,53^{\text {n.s. }} \\
16,6 \pm 0,68^{\text {n.s. }} \\
15,7^{\mathrm{b}}\end{array}$ & $\begin{array}{c}14,4 \pm 0,70^{\text {n.s. }} \\
17,4 \pm 1,23^{\text {n.s. }} \\
15,9^{\mathrm{ab}}\end{array}$ & $\begin{array}{l}14,9^{\mathrm{B}} \\
18,4^{\mathrm{A}}\end{array}$ \\
\hline \multicolumn{5}{|c|}{$\begin{array}{l}\text { Tecido vascular não lignificado } \\
\text { Non lignified vascular tissue }\end{array}$} \\
\hline $\begin{array}{l}\text { Mediana } \\
\text { Median } \\
\text { Basal } \\
\text { Basal } \\
\text { Média(C) } \\
\text { Average }\end{array}$ & $\begin{array}{l}2,1 \pm 0,07^{\text {n.s. }} \\
2,2 \pm 0,27^{\text {n.s. }}\end{array}$ & $\begin{array}{c}1,3 \pm 0,04^{\text {n.s. }} \\
1,2 \pm 0,09^{\text {n.s. }} \\
1,3^{\mathrm{b}}\end{array}$ & $\begin{array}{l}1,4 \pm 0,09^{\text {n.s. }} \\
1,2 \pm 0,04^{\text {n.s. }}\end{array}$ & $\begin{array}{l}1,6^{\mathrm{A}} \\
1,6^{\mathrm{A}}\end{array}$ \\
\hline \multicolumn{5}{|c|}{$\begin{array}{l}\text { Tecido parenquimático } \\
\text { Parenchymal tissue }\end{array}$} \\
\hline $\begin{array}{l}\text { Mediana } \\
\text { Median }\end{array}$ & $82,0 \pm 1,36^{\text {n.s. }}$ & $83,3 \pm 1,45^{\text {n.s. }}$ & $83,8 \pm 0,81^{\text {n.s. }}$ & $83,0^{\mathrm{A}}$ \\
\hline $\begin{array}{l}\text { Basal } \\
\text { Basal }\end{array}$ & $76,0 \pm 2,92^{\text {n.s. }}$ & $81,5 \pm 0,82^{\text {n.s. }}$ & $80,7 \pm 1,34$ n.s. & $79,4^{\mathrm{B}}$ \\
\hline $\begin{array}{l}\text { Média }(\mathrm{C}) \\
\text { Average }\end{array}$ & $79,0^{\mathrm{b}}$ & $82,4^{\mathrm{a}}$ & $82,3^{a}$ & \\
\hline
\end{tabular}

res, os cvs. ROXO e AREIA apresentaram maior área deste tecido. Em outras espécies, como a Brachiaria, a qual possui medula oca, não houve variação em nenhum dos tecidos nas diferentes regiões do colmo (ALVES DE BRITO e RODELLA, 1999). Isto indica que a natureza do colmo pode constituir-se em um elemento de diferenciação para a distribuição dos tecidos. Nestes termos, foi difícil se estabelecer maiores considerações sobre a distância entre os feixes vasculares. Foi observado que no colmo, a distribuição dos feixes vasculares é irregular, não obedecendo em princípio, a nenhum padrão. Dessa forma, ficou prejudicada a tentativa de se estabelecer medidas de distanciamento entre os feixes vasculares no colmo do capim-elefante.

\section{Conclusões}

Aárea ocupadapelo tecidoepidérmiconolimbosereduz com o incremento do estádio de maturação das folhas. É também no limbo que se concentra a maior área de tecido vascular lignificado. A área de tecido vascular lignificado aumenta com a idade dos tecidos, especialmente no colmo.

Os feixes vasculares na bainha encontram-se bastante distanciados em relação a sua distribuição no limbo. No colmo, o estabelecimento de um padrão de distribuição dos feixes vasculares fica prejudicado pela forma irregular com que os mesmos se distribuem.

Somente algumas características podem ser diferenciadas entre os cultivares pelas medidas utilizadas no presente trabalho. 


\section{Referências Bibliográficas}

AKIN, D.E., BURDICK, D. 1975. Percentage of tissue types in tropical and temperate grass leaf blades and degradation of tissues by rumen microorganisms. Crop Sci., 15:661-668.

ALVES DE BRITO, C.J.F., ALQUINI, Y. 1996. A new method for staining botanical material embedded in glycol metacrylate (GMA). Arq. Biol. Tecnol., 39(4):949-951.

ALVES DE BRITO, C.J.F., RODELLA, R.A. Quantificação anatômica da folha e do colmo de Brachiaria brizantha e $B$. humidicola em três níveis de inserção. In: REUNIÃO ANUAL DA SOCIEDADE BRASILEIRA DE ZOOTECNIA, 36, 1999, Porto Alegre. Anais... Porto Alegre: SBZ, 1999. p.41.

ALVES DE BRITO, C.J.F., RODELLA, R.A., DESCHAMPS, F.C. et al. 1999. Anatomia quantitativa e degradação in vitro de tecidos em cultivares de capim-elefante (Pennisetum purpureum Schumach.). Rev. bras. zootec., 28(2):223-229.

ALVES DE BRITO, C.J.F., DESCHAMPS, F.C. Caracterização anatômica de Hemarthria altissima (Poir) Stapf \& C.E. Hubb (Poaceae). In: REUNIÃO ANUAL DA SOCIEDADE BRASILEIRA DE ZOOTECNIA, 35, Botucatu, 1998. Anais... Botucatu: SBZ, 1998. p.675-677.

CHERNEY, J.H., MARTEN, G.C. 1982. Small grain crop forage potential: II. Interrelationships among biological, chemical, morphological and anatomical determinants of quality. Crop Sci., 22:240-243.

ENGELS, F.M., SCHUURMANS, J.L.L. 1992. Relationship between structural development of cell walls and degradation of tissues in maize stems. J. Sci. Food Agric., 59:45-51.

JOHANSEN, D.A. 1940. Plant microtechnique. New York: McGraw Hill Book. 523p.

HANNA, W.W., MONSON, W.G., BURTON, G.W. 1973. Histological examination of fresh forage leaves after in vitro digestion. Crop Sci., 13:98-102.

METCALFE, C.R. 1960. Anatomy of monocotyledons. I-Gramineae. Oxford: Claredon Press. 731p.

RODELLA, R.A., AYOUB, J.F., MAIMONI-RODELLA, R.C.S. 1984. Estudos quantitativos de características anatômicas da folha de Panicum maximum Jacq. E Panicum coloratum L. Rev. de Agricultura, 59(2):163-174.
SALERNO, A.R., VETTERLE, C.P., DESCHAMPS, F.C. et al. 1990. Gramineas forrageiras estivais perenes no Baixo Vale do Itajaí. Florianópolis: EMPASC. 99p. (EMPASC, Boletim Técnico, 49).

VENTRELLA, M.C. 1995. Anatomia quantitativa e composição bromatológica de folha e colmo de três espécies de Cynodon Rich. Botucatu: UNESP, 1995. 127p. Dissertação (Mestrado em Ciências Biológicas - Botânica) - Instituto de Biociências, UNESP, 1995.

VENTRELLA, M.C., RODELLA, R.A, COSTA, C. et al. Anatomia e bromatologia de espécies forrageiras de Cynodon Rich. I. Folha. In: REUNIÃO ANUAL DA SOCIEDADE BRASILEIRA DE ZOOTECNIA, 34, 1997, Juiz de Fora. Anais... Juiz de Fora: SBZ, 1997a. p.3-5.

VENTRELLA, M.C., RODELLA, R.A, COSTA, C. et al. Anatomia e bromatologia de espécies forrageiras de Cynodon Rich. II. Colmo. In: REUNIÃO ANUAL DA SOCIEDADE BRASILEIRA DE ZOOTECNIA, 34, 1997, Juiz de Fora. Anais... Juiz de Fora: SBZ, 1997. p.6-8.

WILSON, J.R. 1976. Variation of leaf characteristics with level of insertion on a grass tiller. II. Anatomy. Aust. J. Agric. Res., 27:355-364.

WILSON, J.R. 1993. Organization of forage plant tissues. In: JUNG, H.G, BUXTON, D.R., HATFIELD, R.D. et al. (Eds.) Forage cell wall structure and digestibility. Madison: ASA/CSSA/SSSA. p.1-32.

WILSON, J.R. Structural and anatomical traits of forage influencing their nutritive value for ruminants. In: SIMPÓSIO INTERNACIONAL SOBRE PRODUÇÃO ANIMAL EM PASTEJO, 1997, Viçosa. Anais... Viçosa: DZO-UFV, 1997. p.173-208. 